\title{
Competition and Innovation in Telecom Sector: Empirical Evidence from OECD Countries
}

\author{
Sheikh Taher ABU \\ Faculty of Business Studies, Jahangirnagar University, Dhaka - 1342, Bangladesh \\ knipuljp@yahoo.co.jp
}

The paper aims to analyze the effect of competition and innovation in OECD next-generation mobile phones (as a proxy for telecom sector) by examining factors affecting the diffusion pattern. A rigorous econometric model is estimated using the mobile telecommunications panel dataset comprised with the 19 OECD countries where at least $80 \%$ data are covered. The econometric model categorizes the variables as: (1) GDP per capita income and mobile user cost, (2) competition policies (3) telecom infrastructure (4) technological innovations (5) others such as role of MVNO (mobile virtual network operators), multiple standards for $3 G$ as for the appropriateness of the outcome. The study represents country specific influence in terms of mobile contents and technological innovations. A new and important empirical finding is that there are still many opportunities available for mobile network operators $(M N O)$ in this region by providing better telecom infrastructure to support technological innovations and to upheaval decreasing trend of average revenue per user (ARPU). Besides, the most important factors are identified as high speeds and necessary time require for porting mobile number.

Keywords: Next-Generation Mobiles; Technological Innovations; Competition Policy, Panel Data Analysis; Standardization

\section{1} Introduction

After digital mobiles, third generation $(3 \mathrm{G})$ technology around the world have come across to a new platform of debate among regulators and policy makers. With an optimistic view, developed countries around the world have taken the first initiative to allocate $3 \mathrm{G}$ spectrum for proper deployment and to meet the criteria of IMT-2000 as standardized by International Telecommunication Union (ITU). Although digital mobiles have ensured faster growth and reached toward saturation within a decade or less, but a different phenomenon is observed for $3 \mathrm{G}$ technologies accept Japan and Korea. Still, several important issues are unobserved and difficult to determine what factors have significant effect on next-generation mobiles.

As Dippon [1] mentioned, "yet, why is the case that only two countries, Japan and Korea, have more $3 \mathrm{G}$ than $2 \mathrm{G}$ subscribers? Similarly, why do leading nations, like the U.S., U.K., and Germany, have $3 \mathrm{G}$ penetration rates of less than $30 \%$ ?" The statements are in some extent difficult to answer, while (2007) [2] mentioned "the Japanese and later other service providers solved the first startup problem for mobile Internet (mobile Internet uses proxy for $3 \mathrm{G}$ ) with entertainment content that was supported by a micropayment system (service providers collect and pass on content fees to content providers) and customized handset that enabled to display this content in a consistent manner, while Western service providers were slow to introduce micro-payment systems and entertainment content due to their initial focus on business users." Although the statement of Funk is backward but it provides two interesting points for mobile Internet deployment such as: entertainment content and micropayment systems. Abu [3] empirically analyzes $3 \mathrm{G}$ deployments in Japan and identified technological innovations such as electronic payment; high-speed access and entertainment services are important factors for the success of $3 \mathrm{G}$ technology. Policy issues, for example mobile number portability (MNP), pay little attention for $3 \mathrm{G}$ deployment. Also, $3 \mathrm{G}$ penetration is not only the question of quantity but also quality. Recent study on broadband gap by Vicente and Gil-de- 
Bernabé [4] mentioned, "How good is it? How fast? And, how fast is fast?" and identified that Japan is found to be the only country of the 42 countries studied currently prepared to deliver quality required for nextgeneration web applications over the next 3 to 5 years in order to meet Broadband Quality Score-an index that combines three key performance parameters for the quality of a connection (upload and download speeds, and latency). For instance, the same statement is applicable to $3 \mathrm{G}$ technology deployment in Japan and Korea.

In general, technological development which is embodied in innovative functions plays significantly important roles in the growth and upheavals of the global 3G market. Particularly, development in contents, value added services which are supplied by related firms formed in the vertical structure, pricing strategies, handset developments; all these have made this small device an increasingly important part for daily life and to emerge new concepts of "Triple Play."

Mobile phone usage has doubled worldwide since 2000 especially after the digitalization of the mobile network, with its first step of mobile technology development. Living standards and economic growth in developing countries are invariably linked to the availability and use of telecom services [5]. There are now approximately 4.45 billion global users for mobile communications (GSM), wideband code division multiple access-high speed packet access (W-CDMAHSPA) subscribers worldwide [6] approaching to $90 \%$ coverage of the human population. That is a significantly faster rate of growth for mobile technology than landline service, which now totals 1.85 billion users a century after it was invented, as well as Internet service, which grew from 400 million users in 2000 to approximately 1.97 billion users by 2010 .

As of 2009, more than 144 countries worldwide have adopted $3 \mathrm{G}$ technologies with 347 W-CDMA commercial operators. Besides, 31 countries are committed to commercialize long-term evolution (LTE) with 64 LTE network providers. But the relative gaps are found in the penetration rate, handset quality and connection speeds. ITU defines mobile broadband as the speed rate of $144 \mathrm{Kbps}$ in motion, while $384 \mathrm{Kbps}$ at a static moment, while LTE defines beyond $3 \mathrm{G}$ that is supposed to provide $100 \mathrm{Mbps}$ downlink and 50 Mbps uplink speed. Moreover, HSPA+ is commercialized and implemented to provide high speeds of up to $21 \mathrm{Mbps}$ in Japanese largest cities and some other developed countries. To meet the criteria of ubiquitous world (u-world) and to implement always-on connection, it is widely believed that fixed broadband cannot act as a complementary tool to mobile broadband. Therefore, connectivity or access to mobile broadband is necessary.

The bulk of the growth in $3 \mathrm{G}$ mobile phone usage came from Japan and South Korea among OECD countries. Such countries now account for more than $90 \%$ of $3 \mathrm{G}$ penetrations, while EU and U.S. reported around 3040\% 3G penetration as of December, 2009. The slow diffusion of $3 \mathrm{G}$ technology is apparent not only in EU or in the US, but it is a worldwide phenomenon. Therefore, this study empirically analyzes what factors contribute the most to determine a country's 3G diffusion pattern.

The structure of the paper is as follows. Section 2 examines the previous literature related to mobile phone deployment. Section 3 addresses the digitalization of global mobile phone services and market trend followed by $2 \mathrm{G}$ and $3 \mathrm{G}$ technologies. Section 4 explains the empirical analysis followed by methodology, data sources, and empirical results. Policy implications are also discussed in this section. In Section 5 conclusions are presented with summary of the results, their implications, and discussion.

\section{Literature Review}

Several studies have focused on mobile phones diffusion patterns but the main determinants of global mobile phone diffusion are still in doubt among regulators and policy makers apart from $3 \mathrm{G}$ technologies. In case of pre-3G mobiles, Ahn and Lee [7] was first to undertake a cross-country modeling of 
mobile services using ITU data for one year. They identified a complementary relationship between mobile phone and per capita GDP. Substitution effect between mobile and fixedtelephone was estimated by Madden and Coble-Neal [8] with ITU 1994-2000 in a lagged dependent variable model, termed by a dynamic model. They find mobile phone can be a substitute for fixed-telephone of many countries. Banerjee and Ros [9] find that technological substitution in some countries and economic substitution in others may explain differential patterns of development in global fixed and mobile telephony. A telecommunications demand model was estimated for residential mainline and mobile telephone service for developing countries for the period 1996-2003 by [5]. Their findings show that mobile phone is not substitute in the wire line market, and in fact may be considered complement. Koski and Krestchmer [10] focused on the effects of standardization through two approaches and conclude that standardization has positive but insignificant effect on the timing of initial entry of $2 \mathrm{G}$ services. Market-mediated standardization policy contribution to the international diffusion of digital mobile phone was investigated by [11]. A rigorous demand model is estimated using global mobile telecommunications panel dataset comprised with 51 countries classified in order to World Bank income categories by [12]. They identified that there are still many opportunities available for mobile phone development in the world propoor nations by providing better telecom infrastructure.

Some researches explained penetration rates using geography and income level [13], income alone [14], Socio-cultural attributes and Internet and telecom use [15] or national industry structure, pricing schemes and feature availability $[16,17]$.

Basically, the focus of the above literatures were based on pre-3G, however, only a few previous studies empirically examined factors affect $3 \mathrm{G}$ take-up. Ishii [18] studied Internet use via mobile phone in Japan. Basically, he compared two major operators and their strategic plan to deploy $3 \mathrm{G}$ at the initial stage. He concluded that at the beginning au (KDDI) was successful because it used the same $800 \mathrm{MHz}$ network and base stations to support 3G deployment. In contrast, NTTdocomo started with constructing new W-CDMA network and required to install new base stations to support $3 \mathrm{G}$ technology. The relationship between handset bundling and the adoption of $3 \mathrm{G}$ and mobile data services were investigated by [19], using a case study, in-depth expert interviews and usage dynamics followed by an empirical framework, found that the penetration of $3 \mathrm{G}$ increased from about 0.5 percent to about 10 percent in one year after the handset bundling ban was lifted in April 2006. Their findings also identified that handset bundling regulation is a possible but risky tool for steering the market.

Bohlin, Gruber and Koutroumpis [20] studied factors that affected the diffusion of $1 \mathrm{G}$, $2 \mathrm{G}$ and $3 \mathrm{G}$ technology. They identified the positive affect of per capita income, urbanization, broadband penetration, and regulation across all generations of mobile technologies. Their findings also indicated that the diffusion of $1 \mathrm{G}$ boosted the adoption process of $2 \mathrm{G}$ networks, but $2 \mathrm{G}$ adoptions negatively affected $3 \mathrm{G}$ technologies. Therefore, $2 \mathrm{G}$ technologies were unaffected by the spread of $3 \mathrm{G}$ technologies.

Okholm, Karlsen, Pedersen, and Tops [21] also studied the relationship between handset bundling and $3 \mathrm{G}$ technology deployment. They identified positive impact of handset bundling on $3 \mathrm{G}$ adoption but argued that strong conclusion is not evident due to limited data.

Evolution of mobile communication and the impact of regulatory intervention on both $2 \mathrm{G}$ and $3 \mathrm{G}$ diffusion were studied by [22]. The authors identified that $3 \mathrm{G}$ was not considered as a new tool of services, but as a tool that would optimize their networks. They further mentioned that $3 \mathrm{G}$ was introduced not as a substitute for $2 \mathrm{G}$ but as a complement to $2 \mathrm{G}$, offering multimedia services in mobile phone.

The effect of technological innovations and competition policies on $3 \mathrm{G}$ technology de- 
ployment in Japan was studied by [3]. He identified that technological innovations in entertainment, electronic payment and highspeed data services are significant determinants of $3 \mathrm{G}$ diffusion not only for whole market but also for major three operators in Japan. The author further examined the policy effect, such as MNP, on 3G technology in Japan and concluded with findings that MNP has more significant effect on a dominant operator, that is, NTTdocomo than small operators.

Dippon [1] examined the determinants of $3 \mathrm{G}$ deployment rates and the effectiveness of various policy tools using several econometric models based on the $3 \mathrm{G}$ diffusion patterns and other attributes of 47 countries. Due to the lack of $3 \mathrm{G}$ spectrum allocation of 6 countries, 41 countries were included for the empirical analysis. The author disclosed that $3 \mathrm{G}$ penetrations could be explained by the time that passed since the deployment of the technology, mobile penetration rates, population density, market concentration, the percentage of pre-paid subscribers, and the size of the population. Further, the author mentioned that early deployment and a competitive market are keys to the mobile technology diffusion.

Based on the literatures surveyed, this paper is aimed at finding the best-suited diffusion factors for $3 \mathrm{G}$ technologies (as a proxy for NGMN) of 19 OECD countries in order to understand the significant determinants of diffusion at a provision of economy, market size, mobile cost, telecom infrastructure, market competition, policy and technological innovation. By studying OECD 3G services using different econometric models, it is hoped to create a basis for future study of $4 \mathrm{G}$ launch around the world. The empirical findings show useful insights for regulators, policy makers, and operators contributing to the further development of the mobile telecommunication market at a national level, especially with respect to the future development of $4 \mathrm{G}$ technologies.

\section{Evolution of Digital Mobile Network and Market Trend}

The digitalization of mobile network was first introduced worldwide during the early 1990s [23]. Denmark, France, Germany launched its first digital mobile phones in 1992, while some countries launched after 2000 such as Bhutan and Colombia with the adoption of GSM or CDMA technology. Since then, mobile phone has shown remarkable growth through its $2 \mathrm{G}$ network until 2000 . After the year 2000, most of the developed countries have demonstrated to upgrade the $2 \mathrm{G}$ network to $3 \mathrm{G}$ via its existing network and proper licensing policy to enhance competition, infrastructure development, $\mathrm{R} \& \mathrm{D}$ development, etc. In addition to a competitive licensing policy and speed-up diffusion that opened the market for $3 \mathrm{G}$ mobiles, market structure design typically entailed simultaneous entry of a relatively large number of firms, that is, the ' $n+1$ rule' (with $n$ being the number of incumbent $2 \mathrm{G}$ mobile operators) was frequently applied to determine the number of $3 \mathrm{G}$ licenses [20]. Consequently, the diffusion process was generally delayed with respect to initial expectations. New technology and lack of suitable handsets associated with other equipment such as base stations to support multimedia access were difficulties in particular. According to Gruber [24], the increase in the number of licenses might not lead to rapid diffusion of $3 \mathrm{G}$ mobile phone, because the envisaged market structure might not be sustainable under competitive conditions. Another problem anticipated was the high value of scarce $3 \mathrm{G}$ spectrum fees which consequently led to high winning bids. For instance, Madden, Saglam, and Morey [25] reported that winning bidders in the UK paid 650 Euro for each potential subscriber. In Germany, winning bidders paid 615 Euro per capita. Therefore, high spectrum prices in different countries hinder $3 \mathrm{G}$ diffusion.

\section{Empirical Analysis}

To examine the variables selected in the analysis, the study utilizes a secondary dataset and conducts methodologies such as: a) 
linear probability model and b) panel data analysis to investigate the role of the aforementioned factors in affecting $3 \mathrm{G}$ diffusion in OECD countries. Models are estimated via ordinary least squares by using data for up to 19 countries depending on information avail- able on study countries. All data are entered in log form so that coefficient estimates may be interpreted as elasticity. Table 1 and 2 provide summery statistics and study countries, respectively.

Table 1. Summary statistics

\begin{tabular}{llllll}
\hline Variable & Mean & Std. Dev. & Min & Max & Obs \\
\hline Subs3G & 6861333 & 15600000 & 1000 & 88100000 & 84 \\
INCOME & 30896 & 13000 & 1108 & 57027 & 95 \\
CHARGE & 1.02 & 0.61 & 0.13 & 2.56 & 71 \\
PDEN & 151 & 128 & 3 & 490 & 95 \\
INPEN100 & 49.90 & 15.33 & 15.00 & 80.41 & 95 \\
COVERAGE & 98.94 & 2.22 & 79.00 & 100.00 & 94 \\
Subs2G & 32300000 & 48700000 & 2459 & 262000000 & 94 \\
ARPU & 417.33 & 172.26 & 90.00 & 893.00 & 95 \\
TELEDEN & 142.00 & 20.24 & 76.95 & 181.39 & 95 \\
MNP_t & 0.21 & 0.41 & 0.00 & 1.00 & 95 \\
MNP_p & 0.47 & 0.50 & 0 & 1 & 95 \\
HSDPA & 0.38 & 0.49 & 0 & 1 & 95 \\
STANDARD & 0.32 & 0.47 & 0 & 1 & 95 \\
3Gcomp & 0.63 & 0.48 & 0 & 1 & 95 \\
MVNOext & 0.79 & 0.41 & 0 & 1 & 95 \\
\hline
\end{tabular}

Due to the lack of data, we collected panel data from 2003-2007 to study and implement actual determinants of $3 \mathrm{G}$ diffusion of OECD countries. Since five years panel data is used, the study envisions and measures factors determine 3G technologies. Dippon [1] indicated two limitations for the availability of $3 \mathrm{G}$ subscribers. First, 3G diffusion can only be measured as the percentage of mobile subscribers who use $3 \mathrm{G}$ handsets. Second, there are many countries report 3G subscribers even though they have not allocated $3 \mathrm{G}$ spectrum. Therefore, a cross-section data was employed instead of time-series data in his study to determine demand for $3 \mathrm{G}$.

Table 2. Countries used in the study

\begin{tabular}{ll}
\hline Australia & Korea \\
Austria & New Zealand \\
Belgium & Poland \\
Chech Republic & Slovak Republic \\
Denmark & Spain \\
Finland & Sweden \\
Germany & Switzerland \\
Greece & United Kingdom \\
Italy & United States \\
Japan & \\
\hline
\end{tabular}

In this study, however, the second problem is not existed since OECD countries have already allocated 3G spectrum except Mexico.
Therefore, Mexico is removed from the empirical analysis. Likewise, we observed another problem that even some regulators 
homepage of OECD countries such as Canada and France do not report 3G subscribers. Therefore, only 19 countries among 30 coun- tries are studied. Table 3 contains variables collected for each country with brief description and sources.

Table 3. Category of variables, definitions and sources

\begin{tabular}{|c|c|c|}
\hline Category & Variable & Definitions and source \\
\hline Dependant & Subs3G & number of $3 \mathrm{G}$ subscribers, ITU,OECD \\
\hline Wealth & INCOME* & GDP per capita income, World Bank \\
\hline Cost of mobile & CHARGE* & price per 3 minutes peak time (in US\$), ITU \\
\hline Market size & $\begin{array}{l}\text { PDEN } \\
\text { POP }\end{array}$ & $\begin{array}{l}\text { population density }\left(\text { per } \mathrm{km}^{2} \text { ), World Bank }\right. \\
\text { total population in study country, World Bank }\end{array}$ \\
\hline Infrastructure & $\begin{array}{l}\text { Network } \\
\text { TELEDEN } \\
\text { INPEN100 }\end{array}$ & $\begin{array}{l}\text { percentage of mobile network coverage, ITU } \\
\text { (mobile + fixed) per } 100 \text { inhabitants, ITU } \\
\text { Internet penetration per } 100 \text { inhabitants, ITU }\end{array}$ \\
\hline Innovation & HSDPA & $\begin{array}{l}\text { HSDPA allocation year, OECD, ITU, and } \\
\text { Regulators homepage }\end{array}$ \\
\hline \multirow{4}{*}{ Competition } & MNP_t & $\begin{array}{l}1 \text { if time to port } 1 \text { day or less; } 0 \text { otherwise, Var- } \\
\text { ious sources }\end{array}$ \\
\hline & MNP_p & 1 if free, 0 if charge applied, Various sources \\
\hline & 3Gcomp & $\begin{array}{l}1 \text { if all providers are allocated to } 3 \mathrm{G} \text { services, } 0 \\
\text { otherwise, ITU }\end{array}$ \\
\hline & MVNOext & 1 if MVNO exist, 0 otherwise, ITU \\
\hline \multirow{3}{*}{ Substitute/complement } & Subs2G & number of $2 \mathrm{G}$ of study country, ITU, OECD \\
\hline & SubsTOT & $\begin{array}{l}\text { total number of mobile phone subscribers, } \\
\text { OECD }\end{array}$ \\
\hline & SubsDIG & $\begin{array}{l}\text { digital subscribers of study country, ITU, } \\
\text { OECD }\end{array}$ \\
\hline
\end{tabular}

*Income and price variables are adjusted to constant 1995 US dollars using World Bank Consumer Price Index

\subsection{Empirical Model and Methodology}

The most widespread method of estimating models of diffusion on pooled cross-section or aggregate time-series data is to use twostage procedure that was first introduced by [26] in his seminal study on hybrid corn. In this first stage, a logistic, or some other Sshaped curve, is imposed on the data on a proportion of the adopters. The second stage consists of using a linear regression to explain the slope coefficient of the fitted curves representing diffusion in terms of various factors. In this study, we propose different econometric approaches to determine actual factors of $3 \mathrm{G}$ take-up. The aforementioned approaches are discussed in the following section.

\subsection{Simple OLS Model}

A first simple model for $3 \mathrm{G}$ take-up was estimated via conventional ordinary least square (OLS) using the most recent data for 41 countries by [1]. In this study, we implement the same methodology at its first stage to test the hypothesis by using simple OLS in order to identify the basic determinants of $3 \mathrm{G}$ deployment. The econometric specification for linear probability model is

$$
\begin{aligned}
& \ln \left(3 G_{i t}\right)=\ln \beta^{\text {Wealth }_{i t}}+\ln \beta^{\text {Cost }_{i t}}+\ln \beta^{\text {Market }_{i t}}+\ln \beta^{\text {Infrastruc ture }_{i t}} \\
& +\ln \beta^{\text {Innovation } s_{i t}}+\sum \beta^{\text {dummies }}+\varepsilon_{i t}
\end{aligned}
$$


where $3 \mathrm{G}$ is the measure of the availability of total number of $3 \mathrm{G}$ subscribers in country $i$ in time period $t$. The disturbance term is denoted by $\varepsilon_{i t}$. The definition of other variables is illustrated in table 2. To meet the assumptions made for $3 \mathrm{G}$ take-up, Table 4 provides empirical results of the linear probability model. The fitted model indicates that CHARGE with coefficient (-0.0751) and INCOME with coefficient (0.8049), have insignificant effect on $3 \mathrm{G}$ deployment. Although INCOME and CHARGE were identified as significant determinants for the diffusion of $1 \mathrm{G}, 2 \mathrm{G}$ or both $[27,7,10,8,5]$, but for $3 \mathrm{G}$ take-up these economic variables have less than $10 \%$ significance level in our study. The estimated INCOME coefficient indicates that a small increase in current GDP per capita income results in a $0.80 \%$ increase in the growth of $3 \mathrm{G}$ subscription. However, the sign condition of both variables have identified significant in terms of demand function. Except economic variables and tele-density (TELEDEN), all variables have $1 \%$ and $10 \%$ significance levels for $3 \mathrm{G}$ deployment. For instance, the existence of mobile virtual network operator (MVNO_ext) has insignificant effect on $3 \mathrm{G}$ deployment. But these empirical results may have major hindrance of unobserved heterogeneity among explanatory variables, therefore, a panel data model is estimated followed by both fixed and random effect models in the following section.

Table 4. Simple OLS estimation

\begin{tabular}{|c|c|c|c|c|c|}
\hline \multicolumn{6}{|c|}{ Dependent variable: Number of 3G subscribers (3G) } \\
\hline & Coefficient & Standard error & t-value & P-value & \\
\hline CHARGE & -0.0751 & 0.2890 & -0.26 & 0.796 & \\
\hline INCOME & 0.8049 & 0.5180 & 1.55 & 0.127 & $\dagger$ \\
\hline PDEN & 1.0890 & 0.1430 & 7.61 & 0.000 & $* * *$ \\
\hline INPEN100 & 1.8355 & 0.6431 & 2.85 & 0.006 & $* * *$ \\
\hline Subs2G & 0.5739 & 0.1567 & 3.66 & 0.001 & $* * *$ \\
\hline TELEDEN & 3.3405 & 2.0697 & 1.61 & 0.113 & \\
\hline MNP_t & 3.5570 & 0.4784 & 7.44 & 0.000 & $* * *$ \\
\hline MNP_p & -0.1390 & 0.3853 & -0.36 & 0.720 & \\
\hline HSDPA & 1.0549 & 0.3816 & 2.76 & 0.008 & $* * *$ \\
\hline 3Gcomp & 1.7299 & 0.4366 & 3.96 & 0.000 & $* * *$ \\
\hline MVNO_ext & -0.8423 & 0.4424 & -1.90 & 0.063 & $*$ \\
\hline constant & -34.7617 & 7.7208 & -4.50 & 0.000 & $* * *$ \\
\hline & Observations & 61 & & & \\
\hline & Countries & 19 & & & \\
\hline R-squared & 0.8233 & & & & \\
\hline $\begin{array}{ll}\text { Adj } & R- \\
\text { squared } & \end{array}$ & 0.7837 & & & & \\
\hline
\end{tabular}

\subsection{Fixed and Random Effect Models}

In this estimation, both of fixed and random effect models are estimated as a special case of simple OLS. It assumes that the dataset being analyzed consists of a hierarchy of different countries used in the study whose differences relate to that hierarchy. Simply, the model specification for panel data is
$Y_{i t}=\alpha_{i}+\beta X_{i t}+u_{i t}$, with $v_{i t}=\alpha_{i t}+u_{i t}$

where $Y$ and $X$ represents independent and dependent variables respectively. Or more specifically the model can be written in log form as:

$\ln \left(3 \mathrm{G}_{i t}\right)=\alpha+$

$\sum \ln \beta_{i t} X_{i t}+\sum \beta_{i t} d_{\text {dummy }}{ }_{i t}+u_{i t}$ 
where $3 \mathrm{G}_{i t}$ is the number of $3 \mathrm{G}$ subscribers of the $i$ th country at time $t, X_{i t}$ is the vector of regressors, $\beta_{i t}$ is the vector of coefficients, $\alpha_{i}=\alpha$ are the fixed effects, and $u_{i t}$ is the error term, then $\alpha_{i}$ assumes a normal distribution with mean zero and a constant vari- ance that allows to estimate the model representing $v_{i t}$ for the standard error. dummy ${ }_{i t}$ is a binary variable which takes either 0 or 1 (Table 3). The result of the random effect model is presented in Table 5.

Table 5. Estimation results for random effect model

\begin{tabular}{llllll}
\hline \multicolumn{5}{c}{ Dependent variable: Number of 3G subscribers (3G) } \\
\hline Coefficient & Standard Error & z-value & P-value & \\
\hline CHARGE & -0.1061 & 0.3454 & -0.31 & 0.759 & \\
INCOME & 0.6638 & 0.8396 & 0.79 & 0.429 & $* * *$ \\
PDEN & 1.0443 & 0.2631 & 3.97 & 0.000 & $* *$ \\
INPEN100 & 2.5148 & 1.1055 & 2.27 & 0.023 & $*$ \\
Subs2G & 0.4811 & 0.2563 & 1.88 & 0.061 & $*$ \\
TELEDEN & 4.7150 & 2.8565 & 1.65 & 0.099 & $* * *$ \\
MNP_t & 3.5055 & 0.8909 & 3.93 & 0.000 & $* *$ \\
MNP_p & -0.1971 & 0.7222 & -0.27 & 0.785 & $* *$ \\
HSDPA & 0.7971 & 0.3784 & 2.11 & 0.035 & $* * *$ \\
3Gcomp & 1.5153 & 0.7686 & 1.97 & 0.049 & \\
MVNO_ext & -1.0991 & 0.8104 & -1.36 & 0.175 & \\
constant & -40.5463 & 10.6069 & -3.82 & 0.000 & \\
\hline \multicolumn{7}{c}{ R-sq } & within & 0.5631 & & \\
& between & 0.8549 & & \\
\hline
\end{tabular}

$* * *, * *$, and $*$ represent $1 \%, 5 \%$, and $10 \%$ significance levels, respectively

The Hausman test is applied to test fixed versus random effect model specifications and it is identified that $\operatorname{prob}\left(\chi^{2}\right)=0.1175$ mentioning (P-value>.05), therefore, the fixed effect model cannot be accepted and excluded from estimation. Although unobserved heterogeneity in variables is not identified, the random effect model ends up with several interesting findings. The results are consistent with simple OLS estimation and offer a meaningful interpretation for understanding the differences in the $3 \mathrm{G}$ diffusion pattern.

In comparison with the simple OLS, in the random effect model, economic variables such as INCOME and CHARGE have no effect on $3 \mathrm{G}$ deployments in the selected countries, although the effect of having both INCOME and CHARGE together appears to raise significant effect on $3 \mathrm{G}$. The positive sign of INCOME and negative sign of CHARGE with significance level is expected for any technology diffusion. Possible explanations are as follows: (i) there exists some form of endogeneity, which leads to possible biasness in the estimated parameters and furthermore it is not possible to identify the effects of endogenous variables [28]; and (ii) reliability of data, especially that related to prices, since various discount schemes are widely offered by all operators and those are not necessarily reflected in price data announced by them. Additionally, other variables find significant and consistent with the simple OLS estimation.

Our specific goal is to test the hypothesis such as how competition policies and technological innovations affect $3 \mathrm{G}$ mobile phone deployment. Although, the number of obser- 
vations of study country is limited but the estimation results end with a good fit.

Countries with high population densities have found as significant at the 1\% level both in simple OLS and random-effects model for 3G diffusion. This result is consistent with finding of [1]. The possible explanation in this case is Japan and Korea; both countries represent high population density among OECD countries. Also, countries with higher Internet penetration (INPEN100) have significant effect for $3 \mathrm{G}$ take-up rates. Bohlin, Gruber and Koutroumpis [20] analyzed that for all generations of mobile technology broadband/Internet penetration have positive effect. Since $3 \mathrm{G}$ technology means Internet and multimedia access via mobile phone, INPEN100 should be complement to 3G mobile phone. For instance, countries with advanced technology such as Japan and Korea both have high penetration of Internet as well as $3 \mathrm{G}$ mobile phone. The same explanation is applicable for countries with higher teledensity (TELEDEN).

In terms of our findings, $2 \mathrm{G}$ mobile phone is complement to $3 \mathrm{G}$ diffusion. The result is inconsistent with [1] and [20]. Both authors identified that $2 \mathrm{G}$ mobile phones have insignificant effect on $3 \mathrm{G}$ diffusion. Two problems might exist: heterogeneity among explanatory variables and limited number of observations. But the estimation results consistent with findings of [22]. However, in some extent the finding may be applicable to ageing subscribers who use mobile phone as a tool for voice only.

MNP is considered as the policy variable for 3G take-up. Since most of the research identified MNP is not possible factor for $3 \mathrm{G}$ diffusion, in this study, however, instead of MNP rollout, the variable categorized into twofold: first, whether number portability takes 1 day or less time, and second, whether there is any fee applies for porting the number. Among study countries, seven countries are found that MNP takes one day or less. Also, there is no charge applies for twelve countries. However, countries with lower MNP time have significant effect on $3 \mathrm{G}$ adoptions. This finding may be of interest to regulators and operators, because higher the days to port may hinder the subscribers to switch carrier. Besides, if any MNP charge applies subscriber may be loose of interest to switch from existing carrier to another. Both of these findings reconfirms that existence of MNP policy may not affect $3 \mathrm{G}$ deployment and provides further evidence to regulators and operators so that they must ensure time and fees for MNP. In the context of MNP, [3] analyzed the influence into Japanese $3 \mathrm{G}$ market and mentioned that except telephone number MNP does not provide other functionality such as e-mail and contents. In fact, if e-mail and contents can be ported, MNP policy may work for $3 \mathrm{G}$ technology.

To switch from $2 \mathrm{G}$ to $3 \mathrm{G}$ technology, data transmission speed was the most essential factors for subscribers. $3 \mathrm{G}$ technology means multimedia facilities in mobile phones. The findings from [3] suggest that network speed is a crucial innovation for $3 \mathrm{G}$ subscribers in Japan who frequently browse websites to download full music, ringing tone melodies, full-access movies, and many other animated gaming sites. To promote high speed, the Ministry of Communication (MIC) encouraged operators to build high speed data services for next generation mobile phones and set up a licensing scheme in August 2004 which specified the $1.7 \mathrm{GHz}$ (FDD system) and $2.0 \mathrm{GHz}$ (TDD system) bands for $3 \mathrm{G}$ mobile phone.

Moreover, [29] reported that three types of data services offered by $3 \mathrm{G}$ technology include:

- Communications-based data services, primarily involving peer-to-peer communications such as messaging (SMS and MMS) and email.

- Transactional data services, including financial transaction services.

- Content-based data services, including music, entertainment-based educational content, games, video, news, transport information, digital mapping system, etc. Different digital content requires different types of speeds. For analog or digital mobile phones, downlink speed of $256 \mathrm{Kbps}$ was sufficient for existing number of services 
provided by the operators. In contrast, $3 \mathrm{G}$ technologies require the bandwidth necessary to deliver increasingly sophisticated mobile content such as ringing tones, full music downloads, video, digital TV, GPS services or even act as electronic wallet. While operators and regulators collaborate to increase network bandwidth, the opportunities for mobile technological innovations will expand.

Table 6. Bandwidth requirements of selected digital content types

\begin{tabular}{llll}
\hline Content & Uplink speeds (in Kbps) & $\begin{array}{l}\text { Downlink } \\
\text { Kbps) }\end{array}$ & speeds \\
\hline Voice call & 64 & 512 \\
Audio streaming & 128 & 1000 & \\
Web browsing & 64 & 4000 & \\
Virtual worlds & 1000 & 8000 & \\
Video conferencing & 1000 & 12000 & \\
Internet Protocol TV & 1500 & 12000 \\
Video on Demand & 1500 & 12000 \\
Online games & 2000 & 12000 & \\
High-definition TV & 10000 & 18000 & \\
\hline
\end{tabular}

Source: OECD Communication Outlook

According to the simple OLS and randomeffects model, HSDPA has significant effect on $3 \mathrm{G}$ mobile phones deployment. The study countries reported HSDPA was launched from 2006 to 2007 and the average downlink speeds confirmed 3.6 Mbps. However, this study has limitations to measure the average uplink speed which is also necessary to act mobile phones to capture the concept of "triple play."

Likewise, [30] reported that the average asynchronous digital subscribers line (ADSL) download speeds in OECD countries around 9 Mbps which are sufficient for a range of existing digital content services, especially for online video or music. Despite expectations regarding mobile innovations, mobile broadband speeds are lower in most of OECD countries except Japan and Korea. Therefore, high speed is necessary for $3 \mathrm{G}$ mobile phone and reconfirms our estimations for mobile phone innovations. Table 6 reports bandwidth requirements for selected digital content types.

3 Gcomp explains if all mobile operators are provided with $3 \mathrm{G}$ licenses, then it takes 1,0 otherwise. Interestingly, the variable has significant effect and confirms ' $n+1$ rule' by [20]. Additionally, existence of MVNO (MVNO_ext) is considered as a proxy for market competition. But this variable has insignificant effect on $3 \mathrm{G}$ deployment.

\subsection{Policy Implications: MNP}

The study presents that deployment of $3 \mathrm{G}$ mobile phones in OECD countries are largely depend on technological innovations, demographical factors and competition policy of mobile phone operators. Findings from empirical analysis and its implications to $4 \mathrm{G}$ development suggest that technological innovations such as HSDPA is an important factor to upgrade $3 \mathrm{G}$ technology. Still, regulators and operators of OECD countries face crucial problem of proper sizing of the $3 \mathrm{G}$ market. As reported, most of countries penetration rates show less than $50 \%$, while the rollout of $3 \mathrm{G}$ already passed 5-9 years since its initial launch. The proper allocation of spectrum, high bandwidth, and value-added services are keys that can commonly upheaval the $3 \mathrm{G}$ market.

\section{Conclusions}

The paper examined 3G mobile phone adoption and diffusion growth in terms of technological innovations and policy. The empirical methods included analysis of $3 \mathrm{G}$ penetration and growth, econometric analysis of simple OLS and panel data models to explore coun- 
try-specific drivers of diffusion growth and approaches to find influence of the selected variables.

The main highlight of $3 \mathrm{G}$ mobile phone innovations is thus HSDPA, particularly, relate to Internet access. In the world, very few countries have been successful with the mobile Internet both for $2 \mathrm{G}$ and $3 \mathrm{G}$ services due to the lack of sound mobile network infrastructures like Japan. Wireless Access Protocol (WAP) in Europe has suffered from low transmission speeds, paucity of content and disenchanted users. Besides those, developing countries in Asia and Africa or even some parts of the U.S suffer from infrastructure to support the high speed Internet or handsets to use e-payment and entertainment services. Regulators must ensure sufficient bandwidth to operators and operators must ensure the advertised speeds to the subscribers so that $3 \mathrm{G}$ technology can be differentiated from $2 \mathrm{G}$ or $2.5 \mathrm{G}$ technology.

This research also offers practical implications to regulators for MNP policy. The main objective of this policy implementation was to make the market more competitive. The presence of MNP or the time that has passed since the introduction of MNP is not statistically significant for $3 \mathrm{G}$ deployments as reported by [1]. Therefore, this research aimed at using time to port for MNP and price for MNP. Both of these issues are important to port the number. Regulators and operators should consider this and implement the policy in terms of subscribers' point of view.

Currently, countries such as Europe, the US or Japan can use iPhone; innovative touch screen phone for the proper use of mobile phones in the perspective of ubiquitous characteristics. This smart phone capability subsequently needs to look at the success of using all functionality in mobile phones. It is said that the world will become the computing interface. The network will go faster, more pervasive and ubiquitous. Eventually, things are communicating with things, broadening the concept of the Web 1.0 to Web 2.0 into a literal metaphor beyond what lives in cyberspace alone. RFID, wearable computers and non-dedicated devices that can shift their function based on the context will emerge. Such computing is dominant technology and emerging concepts like triple play, virtual reality, etc that are possible via mobile phones.

At the same time, relative gaps are observed not only among countries but also the country itself to support technological development such as high speeds and capacity which is promised to provide by operators. While Japan's HSDPA coverage is $100 \%$, the US is suffering digital divides within countries. The underlying reasons should be reconsidered. But this promise of the future also holds lots of challenges for mobile network operators (MNO) comprised with infrastructure and costs. Aside from these little concerns the promise of ubiquitous computing will be realized one way or another.

Penetration of $3 \mathrm{G}$ mobile phone is not subject to economic variables such as INCOME and CHARGE in terms of findings. Instead, the proper allocation of bandwidth and spectrum cost are key factors for $3 \mathrm{G}$ technology. ' $n+1$ rule' worked for $3 \mathrm{G}$ deployment, while more the operators provide $3 \mathrm{G}$ services more the penetration would be. The time to port the number instead of rollout of MNP has significant impact on $3 \mathrm{G}$, therefore, regulators must ensure to operators the time and price for MNP to subscribers.

The empirical analysis, however, reveals limitations on data, proper econometric foundation and actual impact on 3G deployment. Still, lot of debate exist on the $3 \mathrm{G}$ market comprised with spectrum allocation, handset bundling, and the flat-rate charge system for data communications. However, this study aims at providing simple insights and some implementations for $3 \mathrm{G}$ deployment with regard to technological innovation and policy. The future study is expected to cover which innovations such as electronic payment and entertainment can have strong impacts on beyond $3 \mathrm{G}$ or $4 \mathrm{G}$.

\section{Acknowledgement}

The author expresses his heartfelt gratitude to professor M. Tsuji, Graduate School of Applied Informatics, University of Hyogo, for 
his continuous support and encouragement throughout the course of the research and to Dr. Ulrich Heimeshoff, assistant professor, Dusseldorf Institute for Competition Economics, Heinrich Heine University of Dusseldorf, Germany for his comments and suggestion for the early version of the research at $1^{\text {st }}$ ITS PhD seminar, September 2010, Denmark as discussant role.

\section{References}

[1] C. Dippon, "Is faster necessarily better? Third generation (3G) take-up rates and the implications for next generation services," NERA research paper, 2010.

[2] J. L Funk, "Solving the startup problem in Western mobile Internet markets", Telecommunications Policy, vol. 31, no.1, pp. 14-30, 2007.

[3] S. T Abu, "Technological Innovations and 3G Mobile Phone Diffusion: Lessons learned from Japan," Telematics and Informatics, vol. 27, no. 4, pp. 418432, 2010.

[4] M. R. Vicente and F. Gil-de-Bernabé, "Assessing the broadband gap: From the penetration divide to the quality divide," Technological Forecasting and Social Change, vol. 77, no. 5, pp. 816-822, 2010.

[5] C. Garbacz and H.G. Thompson, "Demand for telecommunication services in developing countries," Telecommunications Policy, vol. 31, no. 5, pp. 276-289, 2007.

[6] GSA, "GSM/3G stats, 2010," available at:

http://www.gsacom.com/news/statistics. php4/Accessed (accessed in August 2010).

[7] H. Ahn and M. Lee, "An econometric analysis of the demand for access to mobile telephone networks," Information Economics and Policy," vol. 11, no. 3, pp. 297-305, 1999.

[8] G. Madden and G. Coble-Neal, "Economic determinants of global mobile telephony growth," Information Economics and Policy, vol. 16, no. 4, pp. 519-537, 2004.
[9] A. Banerjee and A. J. Ros, "Patterns in global fixed and mobile telecommunications development: A cluster analysis" Telecommunications Policy, vol. 28, no. 2, pp. 107-132, 2004.

[10] H. Koski and T. Kretschmer,. "Entry, Standards, and Competition: Firm Strategies and the Diffusion of Mobile Telephony," ETLA Discussion Papers, 824, The Research Institute of the Finnish Economy, 2002.

[11] R.J. Kauffman and A.A. Techatassanasoontorn, "International diffusion of digital mobile technology: A couple-hazard state-based approach," Information Technology and Management, vol. 6, no. 2-3, pp. 253-292, 2005.

[12] S. T. Abu and M. Tsuji, "The determinants of the global mobile telephone deployment: An empirical analysis," Informatica Economica, vol. 14, no. 3, pp. 21-33, 2010.

[13] M. Baliamoune-Lutz, "An analysis of the determinants and effects of ICT diffusion in developing countries," Information Technology for Development, vol. 10, no, 3, pp. 151-169, 2003.

[14] P. Rouvinen, "Diffusion of digital mobile telephony: Are developing countries different?," Telecommunications Policy, vol. 30, no. 1, pp. 46-63, 2006.

[15] A.J. Kamssu, "Global connectivity thorough wireless network technology: A possible solution for poor countries," International Journal of Mobile Communications, vol. 3, no. 3, pp. 249-262, 2005.

[16] M. Minges, "Mobile cellular communications in the southern African region," Telecommunications Policy, vol. 23, no. 7-8, pp. 585-593, 1999.

[17] N. Kshetri and M. Cheung, "What factors are driving China's mobile diffusion?," Electronic Markets - International Journal of Electronic Commerce and Business Media, vol. 12, no. 1, pp. 22-26, 2002.

[18] K. Ishii, "Internet use via mobile phone in Japan," Telecommunications Policy, vol. 28, no.1, pp. 43-58, 2004. 
[19] M. Tallberg, H. Hammainen, J. Toyli, S. Kamppari and A. Kivi, "Impacts of handset bundling on mobile data usage: The case of Finland," Telecommunications Policy, vol. 31, no. 10-11, pp. 648659, 2007.

[20] E. Bohlin, H. Gruber and P. Koutroumpis, "Diffusion of new technology generations in mobile communications," Information Economics and Policy, vol. 22 no. 1, pp. 51-60, 2010.

[21] H. B. Okholm, S. Karlsen, T. T. Pedersen and J. Tops, "How do handset subsidies affect incentives to innovate? Economic Theory and Empirical Evidence", Norwegian Post and Telecommunication Authority, Copenhagen Economics, 2008, http://www.npt.no/ikbViewer/ Content/109445/Accessed on July 2010.

[22] L. Fuentelsaz, J. P. Maicas and Y. Polo, "The evolution of mobile communications in Europe: The transition from the second generation to the third generation," Telecommunication Policy, vol. 32, no. 6, pp. 436-449, 2008.

[23] H. Gruber, "Competition and Innovation: The Diffusion of Mobile Telecommunications in Central and Eastern Europe," Information Economics and Policy, vol. 13, no. 1, pp. 19-34, 2001.

[24] H. Gruber, "Radio spectrum fees as determinants of market structure: the con- sequences of European 3G licensing. In: Soete, L. and B. Ter Weel. (Eds.), The Economics of the Digital Society. Edward Elgar, Cheltenham, pp. 89-112, 2005.

[25] G. Madden, I. Saglam and A. Morey, "Auction design and the success of national 3G spectrum assignment," Working Paper No: 10-02, TOBB University of Economics and Technology, Department of Economics, 2010. http://ikt.web.etu.edu.tr/RePEc/pdf/1002. pdf/Accessed on July 2010.

[26] Z. Griliches, "Hybrid corn: An exploration in the economics of technological change," Econometrica, vol. 25, no. 4, pp. 501-522, 1957.

[27] M. G. Dekimpe, M. P. Philip and M. Sarvary, "Staged estimation of international diffusion models: An application to global cellular telephone adoption," Technological Forecasting and Social Change, vol. 57, no. 1-2, pp. 105-132, 1998.

[28] B. H. Baltagi, "Econometric Analysis of Panel Data," Wiley: Hoboken, NJ, 3. ed. 2005.

[29] OECD, OECD communication outlook, OECD Library, 2005.

[30] OECD, OECD communication outlook, OECD Library, 2008.

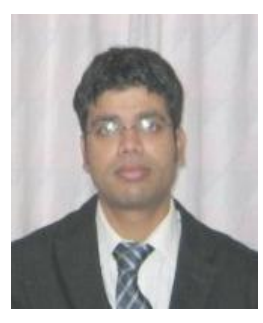

Sheikh Taher ABU is currently an assistant professor of Faculty of Business, Jahangirnagar University, Bangladesh. He received Japanese government scholarship to pursue higher study and completed $\mathrm{MS}$ and $\mathrm{PhD}$ from University of Hyogo, Japan. He was the winner of the O.S. Braunstein award at the PTC'10 conference in HI, USA (2010) and the Best Student Paper award at the $18^{\text {th }}$ Biennial ITS Conference in Tokyo, Japan (2010). Also, he was invited to present his work at CPRsouth4 conference in Sri Lanka (2009) and at the Wireless World Research Forum 24 meeting (WWRF24) in Penang, Malaysia (2010). His teaching areas mainly focus on economics and finance both for undergraduate and graduate students. His research interest includes techno-economic behavior of telecommunications market, financial modelling of ICT business, investment in ICT, economic impact of cloud computing in developing countries, next-generation payment strategies/future of money, etc. He has few publications in international conferences proceedings and quality journals. 